\title{
ACESSO À JUSTIÇA E O IMPACTO DE NOVAS TECNOLOGIAS NA SUA EFETIVAÇÃO
}

\author{
Alexandre Bannwart de Machado Lima* \\ Gustavo Henrique de Oliveira**
}

\section{RESUMO:}

A pesquisa tem por objetivo identificar se as novas tecnologias computacionais e de telecomunicações, tais como inteligência artificial, aprendizado de máquina e blockchain, podem proporcionar ao cidadão maior acesso à justiça, no sentido de que o sistema deve ser igualmente acessível a todos e deve produzir resultados que sejam socialmente justos. $\mathrm{O}$ estudo foi elaborado a partir de pesquisas bibliográficas no campo do direito, da tecnologia e da filosofia, sendo utilizado o método dedutivo. Conclui que a utilização das novas tecnologias contribui para proporcionar ao cidadão um maior acesso à justiça, apesar da existência de dificuldades que precisam ser superadas.

Palavras-chave: Acesso à justiça. Inteligência artificial. Aprendizado de máquina. Blockchain. Tecnologia disruptiva.

\section{ACCESS TO JUSTICE AND THE IMPACT OF NEW TECHNOLOGIES IN THEIR EFFECTIVENESS}

\begin{abstract}
:
The research aims to identify whether new computer and telecommunications technologies, such as artificial intelligence, machine learning and blockchain, can provide the citizen with greater access to justice, since that the system should be equally accessible to all and should produce results that are socially faire. The study was based on bibliographical research in the field of law, technology and philosophy, using the deductive method. It concludes that the use of new technologies contributes to provide citizens with greater access to justice, despite the existence of difficulties that need to be overcome.
\end{abstract}

Keywords: Access to justice. Artificial intelligence. Machine learning. Blockchain. Disruptive technology.

\section{INTRODUÇÃO}

\footnotetext{
* Mestrando em Direito pela UNIMEP. Especialista em Direito Civil e Processo Civil pela OPET/PR. Especialista em Gestão Empresarial pela FGV/EPGE/RJ. Graduado em Direito e Economia pela UEL/PR. Advogado. E-mail: alexandre.blima@hotmail.com

** Doutor e Mestre em Direito Civil pela USP. Graduado em Direito pela PUC/Campinas. Professor de Direito da UNIMEP (graduação e mestrado). Autor de livros sobre Responsabilidade Civil. Advogado. E-mail: gholiveira38@hotmail.com
} 
A sociedade brasileira contemporânea vive um momento de intensa transformação. O desenvolvimento tecnológico, em especial as tecnologias computacionais e de telecomunicações, têm mudado radicalmente a forma como as pessoas trabalham, comunicam-se e acessam informações.

A revolução tecnológica que se apresenta coloca em pauta uma nova agenda para a humanidade, a qual deve estar atenta às complexas consequências da aplicação da inteligência artificial e do uso de ferramentas de machine learning (aprendizado de máquina) na sociedade. Os efeitos decorrentes dessas novas tecnologias já podem ser percebidos no mundo jurídico. O uso intensivo de tecnologia já é uma realidade em muitos setores da atividade humana há vários anos, mas no direito o máximo de "modernidade" parecia ser a troca da velha máquina de escrever pelos editores de texto eletrônicos. Tal percepção de uso da tecnologia nos serviços jurídicos tem mudado radicalmente nos últimos anos, com a incorporação de ferramentas tecnológicas capazes de possibilitar um grande salto de produtividade e de redução de custos.

Essa nova realidade tem impactado tanto a advocacia (escritórios, departamentos jurídicos, firmas de auditoria e consultoria, dentre outras) quanto os órgãos governamentais responsáveis pela prestação jurisdicional. A atividade jurídica, incluída aí a atividade de prestação jurisdicional do Estado, gera diariamente uma variedade e um volume enorme de dados complexos, estruturados e não estruturados, provenientes das mais variadas fontes e em grande velocidade, o que constitui um verdadeiro "big data".

Ante esse "big data" jurídico, somente a utilização de tecnologias disruptivas, ou seja, aquelas que transformam produtos e serviços tradicionalmente caros e complexos e de acesso restrito, em produtos e serviços mais simples, baratos e franqueáveis a uma grande parcela da população, será possível extrair informações dessa grande massa de dados gerada diariamente e utilizá-las para disponibilizar serviços capazes de impactarem significativamente a vida das pessoas, especialmente no sentido de efetivar (verdadeiramente) um dos principais direitos fundamentais inscritos na nossa Constituição Federal: o acesso à justiça.

$\mathrm{O}$ acesso à justiça, previsto na Constituição Brasileira em seu art. $5^{\circ}, \mathrm{XXXV}^{1}$, com abrangência alargada pelos incisos LXXIV $^{2}$ e LXXVIII ${ }^{3}$, é consequência de outra construção

\footnotetext{
${ }^{1}$ XXXV - a lei não excluirá da apreciação do Poder Judiciário lesão ou ameaça a direito;
} 
constitucional: o Estado Democrático de Direito, previsto no caput do art. $1^{\mathrm{o}}$ do texto constitucional (BRASIL, 1988). Assim, do ponto de vista formal, tendo por base o texto constitucional, o Brasil se posiciona como um país que prima, ou deveria primar, pelo respeito aos direitos humanos e pelas garantias fundamentais (garantia dos direitos individuais e coletivos, dos direitos sociais e políticos). $\mathrm{O}$ acesso à justiça é, concomitantemente, direito e garantia de direitos e decorre da noção de igualdade de oportunidades o fato de estar inscrito na Constituição.

Tradicionalmente, o termo acesso à justiça é entendido como a probabilidade de ingressar em juízo para defender eventual interesse violado ou na iminência de sê-lo. Esse é um conceito que tem evoluído no sentido de agregar dimensões de justiça social, incorporando, assim, a expectativa de que o cidadão possa desfrutar de um mínimo garantidor da sua dignidade como pessoa.

A pesquisa foi estruturada em duas partes: a primeira analisa as dificuldades de acesso à justiça no Brasil; a segunda apresenta quais as relações existentes entre tecnologia e acesso à justiça na sociedade contemporânea.

O estudo, empregando o método dedutivo, tem como objetivo verificar, sem a pretensão de esgotar o tema, se o emprego intensivo de inovações tecnológicas disruptivas(inteligência artificial, machine learning, blockchain, dentre outras) no mundo jurídico é capaz de transformar as atividades dos profissionais do direito e das suas organizações, bem como aumentar a eficiência da prestação jurisdicional, e por consequência elevar o grau de efetividade do direito fundamental de acesso à justiça para os cidadãos.

Neste trabalho busca-se identificar se o desafio de tornar efetivo o direito fundamental de acesso à justiça, na sociedade brasileira atual, tem relação com a capacidade do sistema judiciário brasileiro de incorporar tecnologias disruptivas (inteligência artificial, machine learning, blockchain, dentre outras) às suas atividades e processos, especialmente no que tange à prestação jurisdicional estatal, de modo a fazer frente à enorme demanda dos cidadãos em busca de defender os direitos e garantias fundamentais previstos pela Constituição Federal.

\footnotetext{
${ }^{2}$ LXXIV -o Estado prestará assistência jurídica integral e gratuita aos que comprovarem insuficiência de recursos;

${ }^{3}$ LXXVIII - a todos, no âmbito judicial e administrativo, são assegurados a razoável duração do processo e os meios que garantam a celeridade de sua tramitação.
} 


\title{
1 AS DIFICULDADES DE ACESSO À JUSTIÇA NO BRASIL
}

A vida em sociedade provoca a necessidade do estabelecimento de regras a serem obedecidas pelos seus membros, para uma harmoniosa convivência entre as pessoas. Por ser técnica de solução de conflitos, o Direito, que também se apoia na premissa de que $u b i$ societas ibi us ibi ius ubi societas, tem função pacificadora na sociedade (REMEDIO; OLIVEIRA, 2018, p. 172).

O transcurso dos milênios já comprovou que por mais apropriado que seja o sistema normativo de um país ou de um povo, a vida social acarreta invariavelmente os denominados conflitos de interesses que, com o fortalecimento do Estado em um determinado momento histórico, passaram a ser resolvidos por ele. Vale dizer, visando à pacificação social, que o Estado, após a sua fortificação, avocou o poder de dirimir as lides que, até então, conheciam somente a autotutela e a autocomposição como formas de resolução desses conflitos (REMEDIO; OLIVEIRA, 2018, p. 172).

Nesse sentido, e seguindo essa evolução dos povos, nasce um fenômeno jurídico designado de Jurisdição, do latim, juris dictio, com significado léxico de dizer o direito, conceituado como o poder, função, atividade do Estado, decorrente de sua soberania, de aplicar ao caso concreto o direito, em substituição às partes, sempre que provocado (REMEDIO; OLIVEIRA, 2018, p. 172).

Nas palavras de Grecco Filho (2010, p.51):

\begin{abstract}
Costuma-se dividir o sistema de efetivação de direitos em três fases distintas: a autotutela, a autocomposição e a jurisdição. Na primeira, em virtude da inexistência de um estado suficientemente forte para superar as vontades individuais, os litígios eram solucionados pelas próprias forças, imperando a lei do mais forte. Na segunda, as partes abririam mão de seu interesse ou de parte dele, de forma que, por meio de concessões recíprocas, seria possível chegar à solução dos conflitos. Na terceira, própria de um estado de direito, o Estado manteria órgãos distintos e independentes, desvinculados e livres da vontade das partes, os quais, imparcialmente, deteriam o poder de dizer o direito e constranger o inconformado a submeter-se à vontade da lei.
\end{abstract}

O Estado moderno objetiva conceder aos seus cidadãos o bem comum que, avaliado sob o prisma da Jurisdição que é uma de suas funções, se expressa por meio de resolução de conflitos de maneira justa (REMEDIO; OLIVEIRA, 2018, p. 172). 
Do ponto de vista filosófico, a justiça significa um valor ético superior, logo toda ação humana deve se conduzir segundo um certo bem comum ou sem oposição a ele (GIACOIA JUNIOR, 2006, p.109-110).

Da perspectiva da ciência do direito, a justiça representa "o princípio de constituição e funcionamento de sistemas legais e jurídicos, que determina o tratamento equitativo daqueles que estão submetidos a tais sistemas" (MACHADO JUNIOR, 2006, p. 221). De acordo com Kelsen, citado por Machado Junior (2006, p. 220), “o anseio por justiça é o eterno anseio do homem por felicidade, que só pode ser encontrada dentro da própria sociedade. $\mathrm{Ou}$ seja, justiça é a felicidade social, garantida por uma ordem social”.

Para Piovesan (2017, p. 529), “o acesso à justiça constitui uma das mais eficientes formas de realização dos direitos humanos". Sua inserção no conteúdo de tratados e convenções internacionais, bem como nos textos de diversas constituições nacionais deriva do conceito de igualdade, especialmente da "igualdade de oportunidades".

Cappelletti e Garth $(1988$, p. 8) são os responsáveis pelo moderno significado do termo "acesso à justiça":

A expressão acesso à justiça é reconhecidamente de difícil definição, mas serve para determinar duas finalidades básicas do sistema jurídico - o sistema pelo qual as pessoas podem reivindicar seus direitos e/ou resolver seus litígios sob os auspícios do Estado. Primeiro, o sistema deve ser igualmente acessível a todos; segundo ele deve produzir resultados que sejam socialmente justos.

Oliveira (2015, p. 16-17) entende que:

Nessa toada, o princípio da Universalidade da Jurisdição se preocupa com o implemento de uma tutela cada vez mais eficiente, efetiva e eficaz, pois possibilitar o acesso ao Poder Judiciário, por meio do direito de ação, sem a necessária eficácia de modificar a realidade fático-jurídica, quando há necessidade, é a mesma coisa que não garanti-lo. Vale dizer que esse acesso é consagrado, como é cediço, a direito fundamental individual, previsto no art. $5^{\circ}, \mathrm{XXXV}$, da nossa Carta Magna.

Apesar disso, não é difícil constatar, na prática, que uma série de obstáculos contribuem para que o sistema judicial brasileiro tenha pouca eficácia. Apesar da dedicação das pessoas que trabalham na máquina judiciária, barreiras econômicas, organizacionais e processuais corroboram para a percepção de ineficácia da justiça no Brasil.

Segundo Piovesan (2017, p. 530-531), ao pesquisar o problema do acesso à justiça em diversos países, os autores citados acima identificaram barreiras comuns a vários países, as quais prejudicam a proteção integral dos direitos subjetivos. São elas: a) custas judicias, que desencorajam o cidadão a procurar a justiça, posto que não há correlação entre o valor da 
causa e o custo do processo, sendo a justiça tanto mais cara, proporcionalmente para os cidadãos, quanto menos eles disporem de recursos financeiros (problema agravado pela excessiva demora para solução dos litígios, o que gera descrença da população em relação ao poder judiciário); b) possibilidades individuais dos litigantes, que têm relação com o conhecimento que cada um tem em relação aos seus direitos, disponibilidade de recursos e desigualdade de condições; c) problemas específicos para proteção dos direitos difusos, uma vez que originalmente o sistema jurídico, não só do Brasil, mas de outros países também, foi originalmente pensado para resolução de conflitos individuais, mostrando-se inapropriado para solução de conflitos nas sociedades complexas, relacionados com os direitos metaindividuais e coletivos.

Conforme Remédio e Reis Junior (2017, p. 2), a justiça brasileira tem sido desaprovada reiteradamente por oferecer caminhos diversificados e facilitados de acesso ao sistema jurisdicional, ao mesmo tempo em que dispositivos procedimentais atrasam a prestação jurisdicional, elevando em demasia o tempo de duração dos processos.

A fim de que o estado democrático de direito descrito na Constituição Federal cumpra o propósito de garantir apropriada e efetivamente o direito fundamental de acesso à justiça do cidadão, não apenas no seu aspecto formal, mas de fato produzindo resultados socialmente justos, a prestação jurisdicional estatal deve ser realizada por meio de um processo justo, democrático, acessível a todos, se necessário gratuito, sendo assegurados a razoável duração do processo e os meios que garantam a sua celeridade de tramitação (SARLET; MARINONI; MITIDIERO, 2018, p. 855-859).

Para Canotilho (1992, p. 666), aquele que demanda proteção jurídica por meio dos tribunais deve ter assegurada a oportunidade de, em tempo útil, obter uma decisão executória com força de coisa julgada, posto que justiça lenta e tardia é justiça negada.

Gustavo Henrique de Oliveira, ao citar Luiz Rodrigues Wambier, Flávio Renato Correia de Almeida e Eduardo Talamini, assevera que, quando os referidos autores se referem ao tema

tratam do instituto da tutela antecipada, aduzem ter este instrumento processual índole nitidamente constitucional, haja vista o fato de que por vezes o tempo despendido no curso regular de uma ação pode trazer consequências desastrosas ao jurisdicionado. A tutela antecipada foi uma maneira encontrada pelo legislador de mitigar os eventuais danos ocasionados pelo fator tempo no processo, possibilitando a sua eficácia, porquanto garantir o acesso de todos perante um Poder Judiciário ineficiente é a mesma coisa que não garantir. É mister reconhecer que o sistema tem se preocupado, cada vez mais, com a efetividade processual, de forma a permitir a 
sua máxima utilidade implementando, dessa maneira, verdadeiramente, o princípio da universalização da jurisdição previsto no art. $5^{\circ}, \mathrm{XXXV}$, da Constituição Federal de 1988. (OLIVEIRA, 2015, p. 16-17).

De acordo com Mancuso, citado por Bezerra e Braga (2015, p. 127), o texto constitucional de 1988, ao inserir o acesso à justiça no rol das garantias fundamentais do cidadão ampliou o seu alcance. Esse fato, somado ao reconhecimento de um extenso rol de direitos sociais e coletivos, aumentou a expectativa daqueles que buscaram a prestação jurisdicional, diante da demora estatal em entregar a solução dos litígios. Esse contexto gerou uma realidade paradoxal: por um lado a população demonstra frustração por não ver entregue a ela a prestação jurisdicional estatal nos moldes da previsão constitucional, e por outro insiste em procurar o poder judiciário na expectativa de que ele solucione suas demandas.

Para Remédio e Reis Junior (2017, p. 16), a garantia constitucional fundamental do acesso à justiça, medida a disposição de todos que assegura ao indivíduo a proteção jurisdicional estatal rápida, efetiva justa, esbarra nas limitações impostas pelo ordenamento jurídico brasileiro, que também possui princípios e regras que buscam ampliar a segurança das decisões judiciais, por exemplo o direito ao duplo grau de jurisdição que, por outro lado, também contribui para uma maior demora da prestação jurisdicional.

Tal realidade é perceptível ao se analisarem os dados referentes à tramitação de processos na justiça brasileira.

Segundo o relatório Justiça em Números 2018, ano-base 2017, publicado pelo Conselho Nacional de Justiça - CNJ (2018), em 2017 o Poder Judiciário terminou o ano com 80,1 milhões de processos em tramitação, aguardando solução definitiva. Desse montante, 14,5 milhões $(18,1 \%)$ estavam suspensos, sobrestados ou em arquivo provisório, aguardando decisão futura. Ainda segundo o relatório, o ano de 2017 merece destaque por ter tido um incremento de apenas 244 mil casos relativamente ao remanescente de 2016, uma variação de 0,3\%. A Justiça Estadual foi uma das grandes responsáveis por esse resultado, posto que, apesar de registrar uma média de crescimento histórico de 4\% ao ano, em 2017 apontou um crescimento de meros $0,4 \%$. A redução do ritmo de crescimento do acervo também foi verificada em outras esferas judiciais, como nos tribunais superiores: no Superior Tribunal de Justiça a redução foi da ordem de 11\%; no Tribunal Superior do Trabalho diminuição de $7 \%$ e no Tribunal Superior Eleitoral queda de 14,4\%. O único tribunal superior que verificou aumento no estoque de processo foi o Superior Tribunal Militar: crescimento de 17,2\%. 
Ainda, segundo o relatório do CNJ citado acima, ao longo do ano de 2017, houve uma redução de $1 \%$ nos casos novos em relação a 2016: ingresso de 29,1 milhões de processos e baixa de 31 milhões. Outro dado de destaque foi o crescimento dos casos solucionados na ordem de 5,2\%. Desde 2009 houve um aumento acumulado da busca pelos serviços judiciários de $18,3 \%$, crescimento de 19,4 milhões de processos entre 2009 e 2017 . A primeira vez, desde o início da série histórica, em que a quantidade de processos baixados superou a casa de 30 milhões foi em 2017, quando foi nítida a diferença entre a quantidade de casos novos e baixados. Apesar de o volume de novos casos ser inferior ao de casos baixados, o estoque não diminuiu, finalizando 2017 estabilizado no patamar de 80,1 milhões de processos em andamento aguardando resolução. Tal situação é resultado, ao menos parcialmente, dos processos pendentes que retornam à tramitação como, por exemplo, as situações de sentenças anuladas em instâncias superiores. Apenas no ano de 2017 um total de 619.242 processos foram, por algum motivo, reativados. Além dos já citados, outras causas que colaboram para a expansão do estoque de processos em tramitação são as dificuldades na autuação e apuração dos dados, as quais geram inconsistências no sistema.

Analisando as informações do CNJ referentes ao relatório de 2018, ano-base 2017, é possível perceber que os números são de grande magnitude. São mais de 80 milhões de processos tramitando, com ingresso anual de novos casos acima dos 29 milhões. Ainda de acordo com o relatório 2018-2017 tem-se que a estrutura do Poder Judiciário conta em todo o Brasil com 448.694 servidores, sendo 18.168 magistrados Isso custou ao país, nesse período, 90,8 bilhões de reais.

Outro ponto significativo do relatório diz respeito à taxa de congestionamento do Poder Judiciário, que mede o percentual de processos que ficaram represados sem solução, comparativamente ao total tramitado no período de um ano: desde o início da série histórica nunca foi inferior a 70\%. Curiosamente o ano de 2017 foi o primeiro a registrar uma pequena redução de um ponto percentual, porém é um dado que deve ser acompanhado de perto nos próximos anos, visto que "ao longo de 8 anos a taxa de congestionamento variou em apenas 1,5 ponto percentual" (CNJ, 2018, p. 90).

Apesar deste trabalho não ter a intenção de se aprofundar nos detalhes dos números referentes ao Judiciário brasileiro, tais informações são relevantes para se ter ideia do tamanho do desafio que o país enfrenta.

Conforme atesta Mancuso, citado por Bezerra e Braga (2015, p. 129): 
O elevado número de processos leva a conjecturar que talvez seja mais problemático sair da Justiça do que entrar nela. A questão judiciária no Brasil revela-se multifacetada e polifórmica, com várias concausas interagindo, e esse largo espectro, que porventura não vendo sendo tomado em sua integral complexidade, deve estar à base da pouca eficiência das medidas até hoje encetadas, com ênfase no manejo quantitativo da crise numérica dos processos.

E prossegue assim a análise da questão do acesso à justiça no Brasil:

A crise numérica dos processos no Brasil não pode ser avaliada somente sob a ótica processual ou da insegurança jurídica, pois, tais fenômenos não são isolados e se conectam com outras crises e insatisfações que fragilizam as relações sociais e aumentam a litigiosidade. Embora o contingente de demandas judiciais no Brasil aumente espantosamente, as mudanças nos métodos de trabalho estão se modernizando de forma mais vagarosa, o que gera o déficit progressivo na entrada de processos e no encerramento. Ante a impossibilidade, vontade ou meios para resolver suas próprias demandas, muitas vezes, por recusa, ineficiência ou oferta insatisfatória das instâncias que deveriam gerenciar e resolver, acabam desaguando no Poder Judiciário, à sua vez já no limite de sua capacidade, diante do incessante aumento do espantoso estoque de processos represados. (BEZERRA; BRAGA, 2015, p. 129).

Desde a década de 1990, diversas alterações da legislação foram feitas, a fim de equipar o ordenamento jurídico nacional de ferramentas capazes de resolverem litígios de maneira mais eficiente, menos complexa e mais perceptível. Nesse sentido, foram promovidas alterações nos objetivos da ação, do processo e da jurisdição, de modo a permitir que o Judiciário se tornasse capaz de mediar interesses antagônicos e tensões sociais. Dentre as alterações legislativas é possível citar a Emenda Constitucional n ${ }^{\circ} 22$, a criação dos juizados cíveis e criminais, a criação dos juizados de violência doméstica e familiar e a Emenda Constitucional $n^{\circ} 45$, dentre outras (RIBEIRO, 2008, p. 468).

Recentemente uma nova legislação processual civil foi aprovada, também com o objetivo de fornecer à sociedade instrumentos mais eficientes, a fim de realizar uma prestação jurisdicional mais satisfatória. Nessa linha, métodos alternativos de resolução de conflitos têm sido estimulados, direcionando os jurisdicionados a buscarem justiça fora dos tribunais públicos, utilizando a mediação e a arbitragem como meios de se obterem soluções mais rápidas e eficazes, preservando o Judiciário para questões que envolvam direitos indisponíveis. Fundamental também tem sido a opção das partes em buscar a conciliação, como forma de atender às suas expectativas e encurtar o final do processo judicial, posto que dispensa o julgamento de mérito e o cumprimento de sentença (MACHADO JUNIOR, 2006, p. 232). 
Apesar de todo o esforço de evolução normativa e da ampliação das portas de entrada do sistema judiciário brasileiro com vistas ao amplo acesso à justiça, a pretensão de que a prestação jurisdicional seja rápida e eficaz ainda não é uma realidade. A dificuldade de acesso à justiça, no sentido da definição de Cappelletti e Garth (1988), persiste na sociedade brasileira, frustrando assim a efetivação do direito fundamental do cidadão de buscar a tutela jurisdicional estatal, a fim de garantir os seus direitos.

Afinal, se o Poder Judiciário só deve agir quando provocado e se as possibilidades de buscar sua tutela se expandem, é preciso criar condições de superar os gargalos existentes no sistema, de modo que as novas demandas que surgem todos os anos sejam solucionadas de maneira justa e em um prazo razoável, sem que se aumente o estoque de processos em tramitação anualmente.

\section{A RELAÇÃO ENTRE TECNOLOGIA E ACESSO À JUSTIÇA}

A internet, e mais recentemente o surgimento das chamadas "redes sociais", assim entendidas como o "conjunto de relações entre pessoas ou organizações que partilham interesses, conhecimentos e valores comuns, por meio da internet” (REDE SOCIAL, 2018), possibilitaram o surgimento de novos formatos de negócios, novas relações de trabalho e uma nova maneira pela qual o cidadão se relaciona com o Estado. Nesse "novo mundo", conectado e digital, o maior portal de vendas não necessita de estoques, a maior empresa de transportes não precisa ter veículos próprios e a maior companhia de hospedagens não tem um quarto sequer.

Toda nação que almeja vivenciar um estado democrático de direito deve envidar esforços no sentido de tornar a justiça cada vez mais acessível a todas as pessoas, mesmo para aquelas que não têm condições de arcar com o custo financeiro de uma demanda judicial. Lato sensu, o acesso à justiça significa ter os seus direitos preservados por um ordenamento jurídico íntegro e, caso sejam desrespeitados, poder buscar a tutela estatal a fim de receber adequada proteção e justa compensação.

Para Cappelletti e Garth (1988, p. 98) a possibilidade de acesso à justiça se concretiza à medida que as pessoas comuns estejam mais próximas dos tribunais. Os autores entendiam, naquela época, ser conveniente tornar o judiciário mais acessível fisicamente, sugerindo até mesmo que ficasse aberto à noite para que trabalhadores pudessem ser 
atendidos sem a necessidade de faltar ao serviço. Com as atuais possibilidades tecnológicas, essa proximidade dos tribunais pode se dar no campo virtual, com uma capacidade praticamente inesgotável de atendimento, vinte e quatro horas por dia, sem que as pessoas precisem se deslocar fisicamente até o local da prestação jurisdicional e com um alcance territorial limitado apenas pela possibilidade de acesso aos meios de telecomunicações e da rede mundial de computadores ao alcance daqueles que necessitam de solução para suas demandas.

A sociedade atual está inserida em um mundo conectado, e é nesse mundo conectado que os cidadãos manifestam alegrias, frustrações e necessidades, especialmente pelas redes sociais, as quais possibilitam que a informação, nem sempre precisa ou correta, atinja rapidamente um grande número de pessoas. Dessa forma, por meio das redes sociais e dos aplicativos de comunicação pessoal, eventuais insatisfações com a atuação ou omissão dos governos podem ser rapidamente organizadas e exteriorizadas, como as manifestações ocorridas em meados de 2013 que eclodiram após um reajuste nas tarifas de transporte público, as manifestações de apoio à operação Lava Jato e contra a corrupção, as manifestações pelo impeachment da presidente Dilma Rousseff e, mais recentemente, a greve dos caminhoneiros que paralisou o país no fim do mês de maio de 2018. No mesmo sentido, os governantes têm em mãos uma poderosa ferramenta que lhes permite acompanhar e detectar o "humor" da população, podendo comunicar-se diretamente com as pessoas, sem necessariamente depender dos meios de comunicação de massa tradicionais.

Conforme abordado anteriormente neste estudo, segundo Cappelletti e Garth (1988), não basta existir a possibilidade formal de acessar um órgão judicial para que esteja efetivada a garantia constitucional de acesso à justiça, é preciso também que sejam normalmente produzidos resultados favoráveis e socialmente justos, em decorrência do pedido da prestação da jurisdição estatal. Com o intuito de tornar efetivo esse direito fundamental, foram tomadas ações denominadas "ondas renovatórias" pelos referidos autores.

A primeira onda buscou eliminar o obstáculo econômico de acesso à justiça, de modo a prover assistência judiciária gratuita para aqueles que não tinham como suportar os custos do processo (supressão das custas judiciais, advogado fornecido pelo estado). A segunda onda focou na superação da fase do processo como instrumento apenas de defesa dos interesses individuais, concretizando mudanças que permitiram a proteção de interesses difusos e coletivos, especialmente em áreas como proteção ambiental e direito do consumidor, 
dentre outros (Lei da Ação Civil Pública, Código de Defesa do Consumidor, diplomas legais que compõem o microssistema de tutela dos interesses coletivos e difusos). A terceira onda deu azo a uma série de mudanças na estrutura organizacional dos tribunais, levando a criação dos juizados especiais, bem como à simplificação de vários procedimentos processuais, além de estimular que controvérsias possam ser resolvidas não apenas por juízes, mas também por mediadores, conciliadores e pelas próprias partes. Apesar de não prevista nos anos de 1980 por Cappelletti e Barth, uma quarta onda está em andamento e tem relação com os avanços da tecnologia.

Assim como em outras áreas, também no universo jurídico a tecnologia veio para ficar e ocupar um lugar de destaque. Inteligência artificial (IA), machine learning, blockchain, e-discovery e outras tecnologias disruptivas já são utilizadas no mercado jurídico. Os desafios do mundo jurídico, tanto na esfera operacional como no campo cognitivo, são temas obrigatórios nos gabinetes de magistrados e escritórios de advocacia em todo o planeta. A linguagem da tecnologia vem dividindo espaço com o a terminologia jurídica tradicional, seja nos escritórios de advocacia, nos tribunais e em todas as esferas de governo (FERNANDES; CARVALHO, 2018, p. 30).

Trata-se de um caminho sem volta em que nos resta apenas buscar a adaptação necessária para que essas mudanças sejam feitas com o escopo de aprimorar o acesso à justiça e a defesa dos direitos fundamentais.

O professor da Universidade de Harvard Clayton Christensen (2012, p. 255) foi quem disseminou o termo "inovação disruptiva". Segundo ele, disruptiva é a tecnologia que é capaz de modificar um produto usualmente "caro e complexo", disponível para poucos, em alguma coisa bastante "acessível e simples", de modo que muitos possam se beneficiar dela. Esse tipo de evento revoluciona um segmento ou mercado existente, graças à incorporação de "simplicidade, conveniência e acessibilidade" em empresas nas quais complexidade e custos altos são marca registrada. Para facilitar o entendimento do termo, o autor aponta para as seguintes características dos produtos de ruptura: são mais simples, baratos e confiáveis; em regra prometem menores margens de lucro; são comercializados inicialmente em mercados emergentes ou pouco significativos.

A realidade na qual vivemos é interconectada e sofre grande influência do uso que se faz de inteligência artificial e do aprendizado de máquina. O ambiente de negócios está passando por mudanças acentuadas numa velocidade bem grande, cujos resultados ainda são 
pouco conhecidos, impulsionando as organizações para a chamada $4^{\mathrm{a}}$ Revolução Industrial. A utilização de novas tecnologias concomitantemente em várias frentes gera um movimento de aceleração mútua, com grande impacto nas formas de fazer negócio, nas relações comerciais e nas relações de trabalho. A digitalização de atividades aplicadas em setores e processos diversos com finalidades diferentes, tem como meta principal ganhos de eficiência e de produtividade. As grandes transformações provocadas por esse uso massivo de tecnologia nos ambientes de trabalho vão exigir cada vez mais dos gestores das organizações uma reflexão a respeito de como administrar toda essa incorporação de tecnologia sem deixar de lado a preocupação com o bem-estar das pessoas envolvidas (PINHEIRO, 2018, p. 29-30).

Segundo Atheniense (2016), a inteligência artificial, ou computação cognitiva, é a tecnologia que permite uma máquina tomar decisões alicerçadas nos dados por ela processados e nas experiências anteriores, em constante auto aprendizado, de forma similar ao que ocorre no cérebro humano. A computação cognitiva é a tecnologia que capacita computadores e outros dispositivos relacionados a reterem informações, analisá-las e agir a partir delas sem a necessidade de serem programadas para isso. Graças a essa habilidade cognitiva, as máquinas podem processar informações e aprender com esse processo, melhorando assim sua performance de modo independente da ação humana. Esse sistema permite a tomada de decisões pela máquina tomando por referência as informações processadas em momentos anteriores. Isso pode levar a um aperfeiçoamento constante e a um aprendizado autônomo, semelhante ao que ocorre no cérebro humano.

Atheniense (2016) prossegue no tema, descrevendo assim a utilização da sofisticada ferramenta na atividade jurídica:

Por consequência estes serviços atingiram também o setor jurídico, principalmente os escritórios de advocacia, que vem se utilizando de inteligência artificial para alavancar os negócios e aumentar a produtividade. Nesse contexto, os sistemas de inteligência artificial superam os simples mecanismos de buscas ou pesquisa tradicionais e não se confundem com os programas de gestão de processos e negócios, já comuns há algum tempo, nesta atividade. Na inteligência artificial, os computadores por intermédio de um software específico exerce uma atividade cognitiva, ou seja, de contínuo aprendizado no sentido de coletar, processar, pesquisar, analisar semanticamente o conteúdo, compreendendo-o, e realizando tarefas a partir das informações obtidas a partir desse processo, como classificar e apresentar perspectivas de resultados práticos, como sugestões de ação ou tomada decisões. No âmbito jurídico, isso vem sendo utilizado de várias formas, funcionando como um assistente virtual da equipe de profissionais, propiciando no processo de captação de dados e análise de documentos de diversas fontes de consulta tais como legislação, artigos doutrinários, jurisprudência buscas que revelam tendências com rapidez e eficiência podendo abarcar inclusive outras atividades jurídicas. 
Apesar do evidente potencial de aplicações da Inteligência Artificial nas atividades privadas, especialmente na advocacia, o escopo deste trabalho se volta para as possibilidades que se abrem para utilização dessa ferramenta no sentido de otimizar os recursos disponíveis no sistema judiciário estatal.

Não obstante, deve-se reconhecer que o nosso sistema jurídico é repleto de princípios, cláusulas gerais e conceitos jurídicos indeterminados, os quais vão continuar exigindo do aplicador da norma jurídica a utilização da sensibilidade humana necessária para a aplicação do direito justo ao caso concreto, a partir da leitura dos valores mais relevantes para o corpo social.

Num período de orçamentos públicos apertados, é fundamental que cada centavo disponibilizado seja bem aproveitado e que os gestores públicos tenham em mente a necessidade premente de ganhos de produtividade e de redução de custos.

De acordo com Fernandes e Carvalho (2018), em função da natureza arriscada dos projetos de inovação tecnológica, nota-se uma grande dificuldade de o setor público avançar no sentido de contratar serviços com essa característica. A Lei 8.666/93 não foi elaborada pensando em projetos de inovação, afinal não há como garantir que tais projetos serão entregues tal e qual previstos no edital de licitação.

\footnotetext{
A Lei 10.973/2004 (Lei de Incentivo à Inovação e à Pesquisa) foi uma tentativa de criar um ambiente mais propício para a inovação, mas a pouca experiência com a sua aplicação tem mantido o nível elevado de aversão ao risco. O Decreto Presidencial 9.283/2018, que regulamentou essa Lei, detalhou mecanismos inovadores para contratação de inovação tecnológica pelo Estado (FERNANDES; CARVALHO, 2018, p. 32).
}

Apesar dos riscos da legislação, vários órgãos estatais estão desenvolvendo projetos de inteligência artificial, não porque as tecnologias disruptivas estejam na moda, mas sim porque essas tecnologias podem, cada uma a seu modo, resolver um determinado problema na área de atuação do ente governamental.

No que diz respeito a atuação do Judiciário, a parte mais visível do processo de digitalização das suas atividades tem relação com o processo eletrônico. De acordo com o Relatório CNJ (2018, p. 90), no ano de 2017 apenas 20,3\% dos novos processos ingressaram "fisicamente", demonstrando o avançado grau de "digitalização" do sistema, o que facilita tanta a própria prestação jurisdicional como a gestão sistema judicial. 
Afinal, é dessa massa de dados, um verdadeiro big data jurídico, que é possível, com a da utilização de robôs, obter de modo eficiente as informações sobre os processos em tramitação, identificando os casos relevantes e elaborando estatísticas detalhadas que permitirão conhecer melhor a realidade e aumentar a eficiência dos serviços prestados.

O Judiciário brasileiro tem se esforçado no sentido de destinar significativos recursos na busca de automatizar, de informatizar e de modernizar seus processos internos de trabalho e a prestação de seus serviços à sociedade. O resultado disso é a oferta de serviços jurídicos por meio da rede mundial de computadores e a implantação do processo judicial eletrônico. A despeito dos resultados obtidos, há muito ainda que fazer.

Sintonizado com o momento atual, o Supremo Tribunal Federal, agora em 2018, iniciou um projeto de inteligência artificial denominado VICTOR. O objetivo inicial do projeto é colaborar com o trabalho de identificação de quais recursos extraordinários estão vinculados a determinados temas de repercussão geral, realizando o primeiro juízo de admissibilidade dos recursos extraordinários imediatamente após sua interposição, impedindo, desse modo, que recursos relacionados a matérias com repercussão geral cheguem ao STF. A expectativa é que esse projeto, uma parceria do STF com a Universidade de Brasília, agilize a tramitação dos processos e permita redução de custos relacionados a essa atividade o que, de certa forma, contribuirá para uma prestação jurisdicional mais célere e eficiente.

Na visão de Richard Susskind, citado por Peck (2018, p. 139), sendo o acesso à justiça uma espécie de direito que deve ser garantido a todas as pessoas, a utilização de tecnologias que possibilitem o exercício desse direito de uma maneira mais barata, mais célere, mais justa e proporcional deve ser um valor perseguido tanto pelo Estado quanto pelos cidadãos.

Conforme verificado logo acima, a incorporação das inovações tecnológicas nas atividades dos particulares, tais como escritórios de advocacia e empresas afins, que prestam serviços no setor jurídico, tem proporcionado ganhos de produtividade substanciais, reduzindo os custos de operação do sistema e tornando-o mais eficiente, ampliando a possibilidade de que mais pessoas possam se beneficiar dele.

Do mesmo modo, a incorporação dessas tecnologias nas atividades dos entes estatais do sistema judicial começa a impactar positivamente seus resultados, como é possível constatar através da análise das informações apresentadas pelo CNJ. 


\section{CONSIDERAÇÕES FINAIS}

O acesso à justiça, na concepção desenvolvida por Cappelletti e Garth (1988), é um direito fundamental que deve ser efetivado na perspectiva de uma sociedade que se enxerga vivenciando um estado democrático de direito. Os obstáculos que precisam ser superados a fim de garantir esse direito fundamental são significativos e demandam tempo para serem superados, pois envolvem aspectos econômicos, normativos e de estrutura organizacional do sistema judicial.

Uma vez criadas as condições para superação de tais obstáculos, e a sociedade brasileira trabalhou pelo menos, desde o início da década de 1990, nesse sentido, ainda restou trabalho a ser feito, visto que as pessoas ainda encontram dificuldade em concretizar a defesa dos direitos concedidos pela ordem constitucional vigente. Uma variável importante e que explica, ao menos em parte, essa dificuldade é a avalanche de processos judiciais que buscam a prestação jurisdicional estatal anualmente e se acumulam aguardando solução. Por mais recursos humanos e materiais que o Estado destine ao Poder Judiciário para fazer frente a esse desafio, há a permanente sensação de que não será suficiente.

A fim de enfrentar a realidade da Era Digital, do processo eletrônico e de uma sociedade em rede, é necessário incentivar a utilização de ferramentas tecnológicas inovadoras: julgamentos virtuais de processos, comunicação processual por meio de redes sociais, programas de inteligência artificial, arquitetura de computação em nuvem, dentre outros. A transferência das atividades repetitivas para máquinas disponibiliza os recursos humanos para focar nas atividades não rotineiras e que exigem habilidades interpessoais, que podem contribuir para uma prestação jurisdicional mais célere e eficiente.

Nessa perspectiva, o futuro apresenta-se, repleto de desafios. O aparecimento, a disseminação e a consolidação da denominada Quarta Revolução Industrial, a partir da utilização coordenada de várias tecnologias chamadas disruptivas, tais como as da inteligência artificial, da computação em nuvem, dos Big Data, da internet das coisas (IoT), da blockchain, da internet $5 \mathrm{G}$ e dos smart contracts, não só geram significativas transformações e mudanças de paradigmas tecnológicos em diversos setores produtivos de diversas áreas, como tais tecnologias também vêm sendo utilizadas como ferramentas de inovação e de aperfeiçoamento das tarefas no universo jurídico, o que pode contribuir, de modo significativo, para garantir a efetivação do direito fundamental de acesso à justiça. 
Este estudo não permite conclusões definitivas sobre os impactos da incorporação de novas tecnologias no acesso à justiça no Brasil, mas apresenta resultados que indicam que o caminho trilhado até o momento está na direção da melhoria da celeridade e da eficiência da prestação jurisdicional. Um dos indicadores que demonstram que o acerto no investimento em novas tecnologias na solução das demandas da sociedade que são levadas para apreciação do Poder Judiciário são os informes mais recentes do CNJ, especialmente o relatório Justiça em Números de 2018 (ano base 2017). De acordo com ele, o ano de 2017 apresentou o menor crescimento do estoque de processos desde o início da série histórica em 2009, com decréscimo de casos novos em relação ao ano de 2016 e um aumento dos casos solucionados.

A pesquisa mostrou que, ao longo dos anos, o sistema judicial brasileiro incrementou os caminhos de acesso ao sistema, aumentando as portas de entrada, porém não conseguiu o mesmo sucesso com as portas de saída, ou seja, com a solução dos conflitos em tempo razoável e de forma socialmente justa, porém tem apresentado, ainda que timidamente, progressos perceptíveis nos últimos anos, conforme verificado no relatório mais recente do CNJ sobre o tema.

Assim, levando em conta a proposta de acesso à justiça idealizada por Cappelletti e Garth, foram verificados avanços no sentido de tornar a solução dos conflitos sociais e a prestação jurisdicional estatal mais acessíveis a todos, todavia ainda há muito o que fazer em relação à produção de resultados que traduzam uma maior justiça social.

Diante desse desafio, conclui-se que o uso das novas tecnologias computacionais e de telecomunicações, tais como inteligência artificial, aprendizado de máquina, blockchain, dentre outros, podem proporcionar ganhos significativos no sentido de tornar efetivo o direito constitucional de acesso à justiça em seu sentido mais abrangente.

\section{REFERÊNCIAS}

ATHENIENSE, Alexandre. A inteligência artificial e o direito: como a computação cognitiva impactará nas atividades dos profissionais do direito. Jus Brasil, 2016. Disponível em: https://alexandre-atheniense.jusbrasil.com.br/artigos/467690643/a-inteligencia-artificial-e-odireito. Acesso em: $1^{\circ}$ dez.2018.

BEZERRA, Eudes Vitor; BRAGA; Sérgio Pereira. Justiça brasileira: fácil de entrar, difícil de sair um olhar sobre a crise numérica dos processos. In: Congresso Nacional do CONPEDI UFMG/FUMEC/Dom Helder Câmara, 24., 2015, Belo Horizonte. Anais... Florianópolis: CONPEDI, 2015. p. 121-149. Disponível em: 
https://www.conpedi.org.br/publicacoes/66fs1345/4qiqydiv/5Bk84133dqo7a0yQ.pdf. Acesso em: 30 nov. 2018.

BRASIL. Constituição da República Federativa do Brasil, 1988. Disponível em: http://www.planalto.gov.br/ccivil_03/constituicao/constituicaocompilado.htm. Acesso em: 2 dez. 2018.

CANOTILHO, José Joaquim Gomes. Direito constitucional. Coimbra: Livraria Almedina, 1992.

CAPPELLETTI, Mauro; GARTH, Bryan. Acesso à justiça. Tradução de Helen Gracie Northfleet. Porto Alegre: Sérgio Antônio Fabris, 1988.

CHRISTENSEN, Clayton M. O dilema da inovação: quando as novas tecnologias levam empresas ao fracasso. São Paulo: M. Books, 2012.

CNJ - Conselho Nacional de Justiça. Justiça em números 2018: ano-base 2017. Brasília: CNJ, 2018. Disponível em:

http://www.cnj.jus.br/files/conteudo/arquivo/2018/08/44b7368ec6f888b383f6c3de40c32167.p df. Acesso em: 30 nov. 2018.

FERNANDES, Ricardo Vieira de Carvalho; CARVALHO, Angelo Gamba Prata de. The Future: Análise da curva de adoção das tecnologias disruptivas jurídicas (legaltech) e governamentais (govtech), onde estamos e para onde queremos ir. In: FERNANDES, Ricardo Vieira de Carvalho; CARVALHO, Angelo Gamba Prata de (Coord.). Tecnologia jurídica \& direito digital: II Congresso Internacional de Direito, Governo e Tecnologia - 2018. Belo Horizonte: Fórum, 2018. p. 29-44.

GIACOIA JUNIOR, Oswaldo. Pequeno dicionário de filosofia contemporânea. São Paulo: Publifolha, 2006.

GRECCO FILHO, Vicente. Direito processual civil brasileiro. 22. ed. São Paulo: Saraiva, 2010. $1 \mathrm{v}$.

MACHADO JUNIOR, Arnaldo de A. A crise de acesso à justiça no direito brasileiro. Revista da ESMESE, n. 9, p. 219-240, 2006. Disponível em:

https://core.ac.uk/download/pdf/79073265.pdf. Acesso em: 29 nov. 2018.

PECK, Patricia; ROCHA, Henrique. Advocacia digital. São Paulo: Thomson Reuters Brasil, 2018.

OLIVEIRA, Gustavo Henrique de. Responsabilidade civil dos pais pelos atos ilícitos dos filhos capazes. Curitiba: Juruá, 2015.

PINHEIRO, Patricia Peck. Robotização, inteligência artificial e disrupção. In:

(Coord.). Direito digital aplicado 3.0. São Paulo: Thomson Reuters Brasil, 2018. p. $29-33$.

PIOVESAN, Flávia. Temas de direitos humanos. 10 ed. rev. atual. ampl. São Paulo: Saraiva, 2017. 
REDE SOCIAL. Dicionário on-line Infopédia da Língua Portuguesa, 11 dez. 2018. Disponível em: https://www.infopedia.pt/dicionarios/lingua-portuguesa/rede social. Acesso em: $11 \mathrm{dez} .2018$.

REMEDIO, José Antonio; OLIVEIRA, Gustavo Henrique de. Efeitos e limites da revelia à luz dos códigos de processo civil de 2015 e 1973. Revista do Programa de Pós-Graduação em Direito da UFBA, jan-jun 2018, p. 169-194. Disponível em: https://portalseer.ufba.br/index.php/rppgd/article/view/27043/16414. Acesso em: 29 mar. 2019.

REMEDIO, José Antonio; REIS JUNIOR, Valdemir Moreira dos. A garantia do acesso à justiça e o princípio do duplo grau de jurisdição. Revista Cidadania e Acesso à Justiça. Maranhão, jul-dez. 2017. p. 1-20. Disponível em:

https://indexlaw.org/index.php/acessoajustica/article/view/2286. Acesso em: 15 nov. 2018.

RIBEIRO, Ludmila. A emenda constitucional 45 e o acesso à justiça. Revista Direito GV. São Paulo, jul-dez. 2008. p. 465-492. Disponível em:

http://bibliotecadigital.fgv.br/ojs/index.php/revdireitogv/article/view/35160/33965. Acesso em: 29 nov. 2018.

SARLET, Ingo Wolfgang; MARINONI, Luiz Guilherme; MITIDIERO, Daniel. Curso de direito constitucional. São Paulo: Saraiva, 2018. 